\title{
Análise do discurso oficial sobre a humanização da assistência hospitalar
}

\author{
Analysis of the official speech about humanization \\ of the hospital assistance
}

Suely F. Deslandes 1

\begin{abstract}
The term "humanization" has been employed constantly in the health field. It is the base of a wide set of initiatives, even though the concept does not have a clear definition. General$l y$, it refers to a kind of assistance that gives importance to the technical quality of care, associated with recognition of patients' rights, subjectivity and culture. Such concept intends to guide a new praxis in the care production in health. This article, of exploratory mark, aims analyze the speech of the Health Department on the assistance humanization. We investigate the meanings and expectations associates to the humanization idea from the analysis of the official texts, retaking a critical dialog with the authors of the area of public health and of the social sciences. We argue the central ideas of the humanization as opposition to the violence; quality assistance offer, articulating the technological advances with welcoming; professional working terms improvement; and communicational process enlargement, central axis of the texts.
\end{abstract}

Key words Humanized care, Quality of health care, Hospitalization, Communication
Resumo O termo "humanização" tem sido empregado constantemente no âmbito da saúde. É a base de um amplo conjunto de iniciativas, mas não possui uma definição mais clara, geralmente designando a forma de assistência que valoriza a qualidade do cuidado do ponto de vista técnico, associada ao reconhecimento dos direitos do paciente, de sua subjetividade e cultura, além do reconhecimento do profissional. Tal conceito pretende-se norteador de uma nova práxis na produção do cuidado em saúde. Este artigo, de cunho exploratório, visa analisar o discurso do Ministério da Saúde sobre a humanização da assistência. Investigamos os sentidos e expectativas associados à idéia de humanização a partir da análise dos textos oficiais, retomando um diálogo crítico com os autores da área de saúde pública e das ciências sociais. Discutimos as idéias centrais da humanização como oposição à violência; oferta de atendimento de qualidade, articulando os avanços tecnológicos com acolhimento, melhoria das condições de trabalho do profissional, e ampliação do processo comunicacional, eixo central dos textos.

Palavras-chave Humanização da assistência, Qualidade da assistência em saúde, Hospitalização, Comunicação
${ }^{1}$ Instituto Fernandes Figueira, Fiocruz. Av. Rui Barbosa 716, 22250-020, Rio de Janeiro RJ. desland@iff.fiocruz.br 


\section{Introdução}

O termo "humanização" vem sendo utilizado com freqüência no âmbito da saúde. As iniciativas identificadas com a humanização do parto e com o respeito aos direitos reprodutivos das mulheres vêm, há décadas, participando da pauta dos movimentos feministas em saúde. Por sua vez, a humanização da assistência a crianças faz parte de um escopo mais direcionado ao atendimento de bebês de baixo peso, internados em UTI. Alguns modelos de assistência pautados por tal princípio, tais como os projetos Maternidade Segura e o Método Canguru, são amplamente apoiados pelo Ministério da Saúde e pela Organização Mundial de Saúde (OMS, 1996) e considerados referência para a rede pública.

A legitimidade da temática ganha novo status quando, em maio de 2000, o Ministério de Saúde regulamenta o Programa Nacional de Humanização da Assistência Hospitalar (PNHAH) e a humanização é também incluída na pauta da 11a Conferência Nacional de Saúde, realizada em dezembro do mesmo ano. $\mathrm{O}$ PNHAH constitui uma política ministerial bastante singular se comparada a outras do setor, pois se destina promover uma nova cultura de atendimento à saúde (MS, 2000) no Brasil. O objetivo fundamental do PNHAH seria o de aprimorar as relações entre profissionais, entre usuários/profissionais (campo das interações face-a-face) e entre hospital e comunidade (campo das interações sociocomunitárias), visando à melhoria da qualidade e à eficácia dos serviços prestados por estas instituições (MS, 2000). Atualmente o Programa foi substituído por uma perspectiva transversal, constituindo uma política de assistência e não mais um programa específico (provisoriamente intitulada "Humaniza Sus").

Embora constitua o alicerce de um amplo conjunto de iniciativas, o conceito de "humanização da assistência” ainda carece de uma definição mais clara, conformando-se mais como uma diretriz de trabalho, um movimento de parcela dos profissionais e gestores, do que um aporte teórico-prático. O que designa humanizar? Subentende-se que a prática em saúde era (des)humanizada ou não era feita por e para humanos? Tais provocações não raro ainda são feitas, revelando o estranhamento que o conceito propicia. Geralmente emprega-se a noção de "humanização" para a forma de assistência que valorize a qualidade do cuidado do ponto de vista técnico, associada ao reconhecimento dos direitos do paciente, de sua subjetividade e referências culturais. Implica ainda a valorização do profissional e do diálogo intra e interequipes.

Esse conjunto de iniciativas dá voz a demandas antigas na saúde: a) pela democratização das relações que envolvem o atendimento (Carapinheiro, 1993; Svenson, 1996); b) por maior diálogo e melhoria da comunicação entre profissional de saúde e paciente (Adam e Herzlich, 1994; Ong et al., 1995; Caprara e Franco, 1999); c) pelo reconhecimento das expectativas dos próprios profissionais e as dos pacientes, como sujeitos do processo terapêutico (Laplantine, 1991; Helman, 1994; Pitta, 1994; Silva, 1994).

Como ainda não são consensuais os contornos teóricos e mesmo operacionais do que se convencionou designar como humanização, sua abrangência e aplicabilidade não estão inteiramente demarcadas. Considerando a organização e estrutura física das instituições de saúde da rede pública, a formação biomédica, as relações de trabalho e sua lógica de produção, haveria espaço para mudanças estruturais e para a implementação de novos conceitos e práticas, voltados para a humanização da assistência?

Se considerarmos positivamente, esse movimento pode ganhar contornos de uma nova "práxis" para a assistência. Então podemos dizer que aí se constitui um novo campo de possibilidades: tanto para o aumento da qualidade da assistência quanto para uma nova ordem relacional, pautada no reconhecimento da alteridade e no diálogo. Ponderamos, portanto, que a fundamentação teórico-prática neste campo necessita, ainda, de exploração e investimento.

A partir de tais considerações propomos este artigo, de cunho exploratório, visando analisar o discurso oficial produzido pelo Ministério da Saúde sobre o conceito de humanização da assistência. Buscaremos tratar os sentidos e expectativas associados à idéia de humanização a partir da análise dos textos oficiais, retomando um diálogo crítico com os autores da área de saúde pública e das ciências sociais.

\section{Metodologia}

Empreendemos uma análise documental, a partir da proposta de análise de textos (Severino, 1993), orientada pela perspectiva de análise 
de conteúdo, tendo como guia os referenciais da análise temática (Bardin, 1979). Trabalhamos com fontes primárias, incluindo dois dos principais textos oficiais produzidos pelo $\mathrm{Mi}$ nistério da Saúde: o Programa Nacional de Humanização da Assistência Hospitalar (MS, 2000) e o Manual PNHAH (MS, 2000a).

Procedemos primeiramente à fase de exploração textual, identificando os elementos de esclarecimento do texto (autoria, fatos, ideologias e estilo) e a estrutura redacional (capítulos, seções, etc). A leitura flutuante foi realizada, buscando-se delinear os temas presentes no texto. A seguir passamos para a segunda fase, a da análise temática do conteúdo, focalizando as representações, expectativas e argumentos elucidados. Nesta fase buscamos demarcar os núcleos de sentido e suas principais categorias. A última etapa da análise, a fase interpretativa, buscou tecer relações críticas entre as idéias nos documentos, explícitas e implícitas, e o contexto científico, representado por vários textos e autores.

\section{Resultados e discussão}

\section{Significados associados à humanização}

O documento oficial do Programa (MS, 2000) inicia sua argumentação a partir de um diagnóstico de insatisfação dos usuários que diz respeito, sobretudo, aos aspectos de relacionamento com os profissionais de saúde. Essa avaliação ratifica o imaginário social e a opinião pública ao confirmar que, em "número significativo", não seriam só precários mas desrespeitosos e mesmo violentos os cuidados dispensados nos serviços públicos de saúde.

(...) Na avaliação do público, a forma do atendimento, a capacidade demonstrada pelos profissionais de saúde para compreender suas demandas e suas expectativas são fatores que chegam a ser mais valorizados que a falta de médicos, a falta de espaço nos hospitais, a falta de medicamentos (MS, 2000)

(...) Ministro da Saúde J S, ao identificar o número significativo de queixas dos usuários referentes aos maus tratos nos hospitais (....) (MS, 2000)

Assim, resgatar a humanidade do atendimento, numa primeira aproximação, é ir contra a violência, já que esta representa a antítese do diálogo, a negação do "outro" em sua humanidade. Neste primeiro eixo discursivo pode- mos destacar a humanização como oposição à violência, seja física e psicológica que se expressa nos "maus-tratos", seja simbólica, que se apresenta pela dor de não ter a "compreensão de suas demandas e suas expectativas".

No que diz respeito aos maus-tratos físicos e psicológicos, que representam a completa e radical negação dos direitos dos usuários, sua prática é timidamente confirmada pela literatura (Nogueira, 1994; Jewkes et al., 1998). Não é possível, entretanto, afirmar o quanto essas ações são usuais ou corriqueiras. A perpetração explícita da violência parece apontar situaçõeslimite, em que são rompidos contratos básicos de sociabilidade. E, diga-se de passagem, manifestações de violência também podem ter o usuário como agressor, muitas das vezes expressando o desespero de não obter o atendimento após ter peregrinado por várias instituições, entre tantos outros motivos (Petterson et al., 1999; Forrester, 2002; Deslandes, 2002).

Em contrapartida, quanto à violência simbólica do "não reconhecimento" das necessidades emocionais e culturais dos usuários (e da imposição de certos valores morais e comportamentos), seu exercício perpassa a própria historicidade dessa organização. Como vários autores têm demonstrado (Foucault, 1977, 1979; Rosen, 1979), o hospital moderno teve como marca histórica de sua constituição organizacional impor aos "pacientes" o isolamento, a despersonalização e a submissão disciplinar de seus corpos (e subjetividades) a procedimentos e decisões que sequer compreendem. Em outras palavras, essa forma de tratar o "doente", que em nome da "rigorosa prática científica" aparta-o de seu convívio familiar e social e não lhe reconhece discernimento ou competência para tomada de decisões, constituiu, por muito tempo, a tônica da cultura organizacional hospitalar.

A proposta de humanização, ao sugerir a substituição das formas de violência simbólica, constituintes do modelo de assistência hospitalar, por um modelo centrado na possibilidade de comunicação e diálogo entre usuários, profissionais e gestores, busca instituir uma "nova cultura de atendimento". Por sua riqueza, trataremos do tema adiante.

O segundo eixo discursivo identificado nos documentos foi o da necessidade de melhorar a qualidade dos serviços prestados. Neste sentido, a humanização é vista como a capacidade de oferecer atendimento de qualidade, articulando os avanços tecnológicos com o bom relacionamento. 
Nesta empreitada, o Programa destaca a importância da conjugação do binômio "tecnologia" e "fator humano e de relacionamento". Há um diagnóstico sobre o divórcio entre possuir boas condições de alta tecnologia e nem sempre dispor da delicadeza do cuidado, o que desumaniza a assistência. Por outro lado, se reconhece que não ter recursos tecnológicos, quando estes são necessários, pode ser um fator de estresse e conflito entre profissionais e usuários, igualmente desumanizando o cuidado. Assim, embora se afirme que ambos os itens constituem a qualidade do sistema, o "fator humano" é considerado o mais estratégico pelo documento do PNHAH.

(...) as tecnologias e os dispositivos organizacionais, sobretudo numa área como a da saúde, não funcionam sozinhos - sua eficácia é fortemente influenciada pela qualidade do fator $\mathrm{hu}$ mano e do relacionamento que se estabelece entre profissionais e usuários no processo de atendimento (MS, 2000).

O texto considera, portanto, dois aspectos diferenciados que precisam ser reunidos: tecnologia e a boa administração de relacionamentos. Este é um ponto interessante ao debate. Segundo Merhy et al.(1997), o emprego de tais interações, voltadas para a produção do cuidado, também representa uma forma de tecnologia, a "tecnologia leve" e constitui um elemento crucial de gestão. Justamente nos territórios dessas "tecnologias leves", isto é, que dizem respeito à produção de vínculos, acolhimento, autonomização e de gestão do processo de trabalho, ocorrem atualmente as principais reestruturações produtivas do setor saúde (Merhy, 2002). Para o autor, as transições tecnológicas na saúde estão inscritas no modo de atuação do trabalho vivo em ato e nos processos de gestão do cuidado (Merhy, 2002). Aí se constitui a arena de embate entre modelos médicos neoliberais e aqueles oriundos do movimento sanitário, que defendem um modelo de atenção orientado pela "radical defesa da vida".

Desconsiderar tal debate pode gerar uma atribuição de incompatibilidades, de maior resistência entre os que trabalham com o que há "de objetivo" (tecnologias) e com os que trabalham com o "subjetivo" (relacionamentos), além de ignorar o quão potente são, por exemplo, as tecnologias de escuta e de negociação das regras comportamentais e organizacionais.

O terceiro eixo discursivo traz a idéia de humanização como melhoria das condições de trabalho do cuidador. $\mathrm{O}$ documento menciona que outras ações paralelas e integradas estariam sendo desenvolvidas para melhoria das condições de infra-estrutura, seja das instalações físicas, renovação de equipamentos, etc. Percebe-se constante preocupação do discurso em não parecer que há uma proposta de substituição das condições estruturais da qualidade do atendimento, reconhecidos como fundamentais, por um modelo baseado somente "na boa relação". Traz, inclusive, como expectativa que esse processo de humanização se traduza como uma melhor qualidade de atendimento à saúde do usuário e de melhores condições de trabalho para profissionais (MS, 2000). No caput do PNHAH considera-se que para tal tarefa é necessário cuidar dos próprios profissionais da área de saúde, constituindo equipes de trabalho saudáveis (MS, 2000).

Finalmente, como costura de todas as demandas e problemas diagnosticados, os documentos apontam a deficiência do diálogo, a debilidade do processo comunicacional entre profissionais e usuários e entre profissionais e gestores, repercutindo de forma negativa no cuidado prestado. $\mathrm{O}$ desrespeito à palavra e a falta de troca de informações, a debilidade da escuta e do diálogo promoveriam a violência, comprometeriam a qualidade do atendimento e manteriam o profissional de saúde refém das condições inadequadas que não raro lhe imputam desgaste e mesmo sofrimento psíquico. Assim, a humanização também é vista como ampliação do processo comunicacional, sendo esta sua diretriz mais central da proposta de humanização, que será discutida a seguir.

\section{O conceito-chave de humanização}

Não há definições mais precisas sobre o conceito no corpo do documento do PNHAH, apenas referências à necessidade de respeitar $\mathrm{o}$ "outro" "como um ser singular e digno" (MS, 2000). No Manual do PNHAH o tema é desenvolvido, apontando o ser humano como um ser de linguagem e, portanto, capaz de construir redes de significados que, ao serem compartilhadas, conformam uma identidade cultural. Assim, o desrespeito ao estatuto ético da palavra cria as condições de arbítrio e violência (quando a palavra fracassa somos também capazes das maiores arbitrariedades) (MS, 2000a).

Poderíamos dizer que o documento possui algumas afinidades com a perspectiva hermenêutica gadameriana. Para o filósofo Gadamer (1997), toda compreensão é um exercício her- 
menêutico e o estudo da linguagem é o caminho para a análise dos significados. O autor define que a linguagem é o que constitui o ser como ser de relações: a linguagem é a "casa-doser". Desta forma, linguagem e realidade estão profundamente articuladas. O mundo só é "mundo" na medida em que vem à linguagem e a linguagem é real na medida em que o mundo é nela representado, constituindo implicitamente o pressuposto que a linguagem constitui caráter universal do humano (Heckman, 1986).

Nesta perspectiva, humanizar é garantir à palavra a sua dignidade ética, em outros termos, o sofrimento, a dor e prazer expressos pelos sujeitos em palavras necessitam ser reconhecidas pelo outro (MS, 2000a), dado que as coisas do mundo só se tornam humanas quando passam pelo diálogo com os semelhantes (Betts, 2003). Cembranelli (2003) argumenta, neste modelo de entendimento intersubjetivo, que no projeto de humanização se vislumbra uma nova ética, ancorada no princípio da linguagem e na ação comunicativa. Cabe ainda lembrar que a comunicação não verbal também figura como expressão do humano e de sua busca por ser compreendido (Silva, 2002).

A possibilidade comunicacional passa, então, a constituir a referência conceitual mais importante, pois como resume o texto "sem comunicação não há humanização" (MS, 2000a). A "palavra", tanto de usuários quanto de profissionais, precisaria ter, portanto, lugar mais relevante no cotidiano institucional.

O que o texto oficial não problematiza, entretanto, é a natureza sociológica dessa (im)possibilidade comunicacional. Se o ser humano é potencialmente capaz de compreender outro ser humano, porque ambos são dotados de linguagem, o jogo das interações sociais, as relações de saber-poder, de trabalho, de gênero e de status podem constituir fortes impeditivos para o diálogo. Como aponta Habermas (1987) no debate com Gadamer, há impossibilidades comunicacionais que devem ser levadas em conta para que os espaços de diálogo tenham bases mais viáveis de se efetivarem.

O texto oficial reconhece como uma dessas impossibilidades o uso de uma objetividade científica utilitarista. Para isso, o documento ministerial invoca mais uma vez a oposição ciência-tecnologia versus dignidade ética da palavra. Chega mesmo a fazer afirmações categóricas e inconciliáveis como: $o$ ato técnico, por definição, elimina a dignidade ética da palavra, pois esta é necessariamente pessoal, subjetiva, $e$ precisa ser reconhecida na palavra do outro (MS, 2000a). Segundo o texto, a "ciência" (leia-se a biomedicina) teria reduzido o estatuto da palavra à mera busca de informação para a composição da anamnese. Betts (2003), um dos autores do Manual do PNHAH, amplia o debate sobre as impossibilidades da comunicação, presentes nos modelos de assistência e nas motivações que mobilizam o cuidado com quem sofre. Com base em Caponi, Betts aponta os modelos sustentados na compaixão, na lógica utilitarista da promoção da maior felicidade para o maior número de pessoas e na tecnociência. Todos seriam desumanizadores. O primeiro por se sustentar numa relação assimétrica entre benfeitor e assistido; o segundo por diluir as diferenças; e o último por reduzir o diálogo à busca objetiva de informação. $\mathrm{O}$ autor irá defender que somente o modelo motivado pela solidariedade, realizado pelo encontro intersubjetivo e mediado pela palavra é capaz de promover a humanização.

Se enfocarmos a relação do profissional de saúde-paciente, delimitada no contexto do exercício da racionalidade médico-científica, perceberemos que as bases desta comunicação de fato se estreitam. A objetividade positivista, modelo por excelência da medicina científica, vai defender a idéia da neutralidade e exterioridade em face do objeto de estudo (que não mais será o doente, mas a doença). O doente passará então a ser visto como o corpo doente, será o porta-voz da doença e sua narrativa será filtrada, conduzida de forma ortopédica à clareza e objetividade das informações desejadas pelo médico (Hydén, 1997; Camargo Jr., 1998). Desde o século 19, mais precisamente em 1894, o médico McIntire (Nunes, 1999) já apontava as barreiras comunicacionais dessa interação tão especial, sendo o uso do jargão médico percebido, desde então, como uma linguagem diferente e interdita aos leigos, constituindo um obstáculo a mais.

Em contrapartida, seria possível invocar as tradições indiciárias e mesmo hermenêuticas da prática médica (Hunter, 1993; Barry et al., 2000; Caprara, 2003). Em outros termos, defende-se que a medicina se realiza a partir de um exercício de interpretação, cuja matériaprima são as informações, sinais e histórias contadas pelos pacientes e seus familiares e que é preciso fortalecer o viés humanista da medicina. Todavia, tais autores não desconhecem que essa "hermenêutica" se produz hegemonicamente a partir de uma troca desigual, entre 
cliente e médico, gozando este último a prerrogativa hierárquica de conduzir o relato do doente, interferir com outras perguntas ou mesmo interrompê-lo.

Tais ponderações nos fazem lembrar que as interações entre os atores (profissionais e pacientes) são influenciadas por lógicas culturais que as antecedem. Assim, para pensar as (im)possibilidades comunicacionais entre os sujeitos na organização hospitalar é preciso pensar a própria cultura organizacional. Dois aspectos de uma fina dialética aí se esboçam: seja da cultura organizacional, como conjunto de referências compartilhadas, que condiciona todo um sistema de regras que vai orientar as formas de gestão e a lógica de ação dos atores, seja a capacidade de os atores influenciarem a mudança das regras, e conseqüentemente a cultura (Rivera, 2003). Em outros termos, se a cultura organizacional se constitui a partir do agir comunicativo dos seus agentes, em processos de aprendizagem e em busca de consenso, suas configurações simbólicas podem ser questionadas em um nivel discursivo (Rivera, 2003).

Os documentos ministeriais analisados parecem se afinar a este debate de inspiração habermasiana e indicam nas entrelinhas que as possibilidades comunicacionais só se ampliam se toda a cultura de atendimento hospitalar caminhar para um novo modelo, para "uma nova cultura de atendimento". Esta só se viabilizaria se for incentivada uma abertura de diálogo, do nível de gestão à tessitura mais cotidiana do encontro entre profissionais, profissionais e usuários.

\section{"Uma nova cultura de atendimento"}

Como já visto, a meta final do PNHAH é promover uma mudança na cultura de atendimento em saúde no Brasil (MS, 2000). Por sua centralidade, caberia explorar o conceito de "mudança cultural" - tão pouco explicitado nos dois documentos oficiais. Tal conceito pode ser entendido inicialmente como qualquer alteração na cultura, sejam traços, complexos, padrões ou toda uma cultura, o que é mais raro (Lakatos, 1995), ocorrendo de forma lenta ou acelerada, envolvendo diferentes graus de resistência e adesão.

A díade "ordem e mudança" sempre constitui um dos problemas-chave do escopo teórico da sociologia. Ordem se refere a qualquer ação padronizada ou qualquer regularidade exibida no comportamento das pessoas (Skidmore, 1976) e mudança designaria algum tipo de alteração nos padrões das relações sociais (Idem). Seria, portanto, impossível pensar tais termos separadamente: para compreender as mudanças é preciso analisar a ordem estabelecida. Assim, ainda há que se ter em conta que a cultura organizacional do hospital é hegemonicamente calcada numa ordem médico-profissional e discutir suas bases, limites, abrangência e os elementos favoráveis a novas práticas nos parece etapa primordial a uma proposta de mudança.

Nos documentos analisados, os valores de solidariedade e alteridade são considerados norteadores das mudanças culturais da assistência. O respeito ao outro como um ser autônomo e digno é visto, portanto, como condição sine qua non a um processo de humanização (MS, 2000). Essa assertiva pressupõe logicamente conhecer quem é esse "outro", suas expectativas, suas representações e práticas.

Eis aí uma questão nevrálgica. Quem é esse "outro"? Profissionais e usuários? No que concerne aos usuários, o quanto deles se conhece para pressupor que os profissionais de saúde saberão corresponder a suas expectativas? Poderíamos, à luz da experiência empírica, identificar algumas leituras paternalistas, quando o profissional julga saber o que é o melhor para o paciente e tenta prover os meios para satisfazer tais pretensas expectativas, o que não dá resposta satisfatória ao problema. Quais são os mecanismos de "permitir a voz", a livre expressão desses usuários, de facilitar a verbalização de suas demandas, além dos espaços mais formais das ouvidorias?

Finalmente, embora não seja o foco do artigo, torna-se inevitável refletir sobre os meios apontados no texto como eficazes para transformar uma cultura. A via da "formação" parece ser privilegiada nos documentos. Obviamente não se muda uma cultura de assistência unicamente com capacitações dirigidas aos profissionais. Mas, certamente, um investimento sério na formação (inclusive desde a graduação) pode, de fato, fortalecer idéias outrora consideradas utópicas ou fora do âmbito e do "papel" da assistência. Isso pode dar subsídios para que no curso da história (seja de curta, média ou longa duração) e no campo da negociação da ordem política de gestão, os agentes de uma determinada organização constituam novos parâmetros para ação, introduzindo mudanças na cultura da assistência. Rivera (2003) pondera que para mudar as regras do jogo organizacional e as bases da cultura é preciso ir 
além da mudança das "estruturas mentais". Torna-se fundamental um projeto de gestão que democratize as estruturas de poder, que fortaleça a comunicação, desenvolva formas de avaliação e se comprometa com a prestação de contas. $\mathrm{O}$ autor chega a enunciar que mais comunicação é a estratégia genérica para a mudança cultural (Rivera, 2003). Tais orientações também estão nos documentos do PNHAH; contudo, permanece aberta a lacuna sobre as formas de garantir ao usuário maior eqüidade no processo comunicacional.

\section{Conclusões}

Estamos convencidos de que o rico debate sobre a cultura assistencial e sobre a importante proposta de práxis trazida pela proposta de humanização pode contribuir para a reflexão mais crítica dos modelos e ações em saúde.

Longe de qualquer pretensa neutralidade axiológica, demarcamos um lugar nesse debate e afirmamos uma posição ideológico-científica. Acreditamos que apesar da polissemia do conceito de humanização da assistência e da amplitude possível das práticas que se auto-intitulam como "humanizadoras", esse projeto/processo pode propiciar uma contribuição para a melhoria da qualidade da atenção prestada. Pode significar um novo modelo de comunicação entre profissionais e pacientes e quiçá novas práticas cuidadoras. Quem sabe construindo um cuidado, como defende Ayres (2003), responsável porque comprometido

\section{Referências bibliográficas}

Adam P \& Herzlich C 1994. Sociologie de la maladie et de la médecine. Nathan Université, Paris.

Ayres JRCM 2003. Novos discursos e velhas práticas em saúde pública: o cuidado como filosofia para um sanitarismo em reconstrução. Documento apresentado no VII Congresso Latino-Americano de Ciências Sociais e Saúde. Angra dos Reis. (Mimeo)

Bardin L 1979. Análise de conteúdo. Edições 70, Lisboa.

Barry CA, Stevenson F, Britten N, Barber N \& Bradley C 2001. Giving voice to the life-world. More humane, more effective medical care? A qualitative study of doctor-patient communication in general practice. Social Science and Medicine 53(4):487-505. com a construção de projetos humanos, ou melhor dizendo projetos de felicidade.

Destacamos, dentre muitos possíveis, dois pontos dessa proposta que acreditamos merecer ainda maior reflexão. O primeiro diz respeito à concepção da suposta díade "tecnologia e fator humano". Superar tal leitura é etapa rumo à construção de um olhar ampliado sobre a produção do cuidado em saúde, incluindo as tecnologias leves no arsenal dos saberes e competências de saúde. O segundo concerne à questão da mudança cultural e os meios sugeridos para tal, especialmente a proposta de maior capacidade comunicativa como fundante de uma assistência humanizada. Tais idéias serão inócuas se não forem valorizadas as expressões das expectativas e demandas dos próprios usuários-pacientes, reconhecendo sua autonomia e legitimidade simbólicas, cujas manifestações, a princípio, não são delegáveis a tradutores-intérpretes.

Outro aspecto fundamental e pouco explorado nos documentos diz respeito às condições estruturais de trabalho desse profissional de saúde, quase sempre mal remunerado, muitas das vezes pouco incentivado e sujeito a uma carga considerável de trabalho. Humanizar a assistência é humanizar a produção dessa assistência.

Positivamente, as idéias de humanização como antítese da violência e da incomunicabilidade reforçam a posição estratégica das ações centradas na ética, no diálogo e na negociação dos sentidos e rumos da produção de cuidados em saúde.
Betts J 2003. Considerações sobre o que é humanizar. Disponível em <www.portalhumaniza.org.br/ph/ texto.asp?id=37>. Capturado em 9/10/2003.

Camargo Jr. KR 1998. Medicina, médicos, doenças e terapêutica: exame crítico de alguns conceitos. Série Estudos em Saúde Coletiva 170. IMS-UERJ.

Caprara A 2003. Uma abordagem hermenêutica da relação saúde-doença. Cadernos de Saúde Pública 19(4): 923-931.

Caprara A \& Franco ALS 1999. A relação paciente-médico: para uma humanização da prática médica. Cadernos de Saúde Pública 15(3):647-654.

Carapinheiro G 1993. Saberes e poderes no hospital. Uma 
sociologia dos serviços hospitalares. Afrontamento, Porto.

Cembranelli F 2003. Um projeto de humanização: para que, para quem? Disponível em <www.portalhuman iza.org.br/ph/texto.asp?id=49>. Capturado em 9/10/ 2003.

Deslandes SF 2002. Frágeis deuses: profissionais de emergência entre os danos da violência e a recriação da vida. Fiocruz, Rio de Janeiro.

Forrester K 2002. Agression and assault against nurses in the workplace: practices and legal issues. J. Law. Med. 9(4):386-391.

Foucault M 1977. Nascimento da clínica. Forense Universitária, Rio de Janeiro.

Foucault M 1979. Microfísica do poder. Graal, Rio de Janeiro.

Gadamer HG 1997. Verdade e método. Traços fundamentais de uma hermenêutica filosófica. Vozes, Petrópolis.

Habermas J 1987. Dialética e hermenêutica. L\&PM, São Paulo.

Heckman SJ 1986. Hermenêutica e sociologia do conhecimento. Edições 70, Lisboa.

Helman C 1994. Cultura, saúde e doença. Artes Médicas, Porto Alegre.

Hunter KM 1993. Doctors' stories. The narrative sctrutures of medical knowledge. Princeton University Press, Princeton.

Jewkes R, Abrahams N, MVO Z 1998. Why do nurses abuse patientes? Reflections from South African obstetric service. Social Science and Medicine 47(11): 1781-1795.

Lakatos EM 1995. Sociologia geral. (6ạ. ed.) Atlas, São Paulo.

Laplantine F 1991. Antropologia da doença. Martins Fontes, São Paulo.

Merhy EE et al. 1997. Em busca de ferramentas analisadoras das tecnologias em saúde: a informação e o dia a dia de um serviço, interrogando e gerindo trabalho em saúde, pp. 113-150. In EE Merhy \& R Onocko (orgs.). Agir em saúde: Um desafio para a saúde pública. Hucitec, São Paulo.

Merhy EE 2002. Saúde: a cartografia do trabalho vivo. Hucitec, São Paulo.
MS (Ministério da Saúde) 2000. Programa Nacional de Humanização da Assistência Hospitalar. Brasília. (Mimeo)

MS (Ministério da Saúde), 2000a. Manual do PNHAH. Brasília. (Mimeo)

Nogueira MI 1994. Assistência pré-natal. Práticas de saúde a serviço da vida. Hucitec, São Paulo.

Nunes ED 1999. Sobre a sociologia da saúde. Origens e desenvolvimento. Hucitec, São Paulo.

OMS 1996. Care in normal birth: a practical guide. Maternal and newborn health / Safe motherhood unit family and reproductive health. World Health Organization, Genebra.

Ong LM, Haes JCJM, Hoos AM \& Lammes FB 1995. Doctor-patient communication: a review of the literature. Social Science and Medicine 40(7):903-918.

Petterson B, Leadbetter D \& Bowie V 1999. Supporting nursing satff exposed to violence at work. International Journal of Nursing Studies 36:479-486.

Pitta A 1994. Hospital: dor e morte como ofício. (3a ed.). Hucitec, São Paulo.

Rivera FJU 2003. Cultura e liderança comunicativa, pp. 185-218. In FJU Rivera (org.). Análise estratégica em saúde e gestão pela escuta. Fiocruz, Rio de Janeiro.

Rosen G 1979. Hospitais, atenção médica e política social na Revolução Francesa. O hospital - sociologia histórica de uma instituição comunitária, pp. 271300; 317-334. In G Rosen. Da polícia médica à medicina social. Graal, Rio de Janeiro.

Severino AJ 1993. Metodologia do trabalho científico. Cortez, São Paulo.

Silva CO 1994. Curar adoecendo. Um estudo do processo de trabalho hospitalar em busca da saúde, da inventividade e da vida. Dissertação de mestrado. ENSP/ Fiocruz, Rio de Janeiro.

Silva MJP 2002. O papel da comunicação na humanização da atenção à saúde. Bioética 10(2):73-88.

Skidmore W 1976. Pensamento teórico em sociologia. Zahar, Rio de Janeiro.

Svenson R 1996. The interplay between doctors and nurses - negotiated order perspective. Sociology of Health and Ilness 18(3):379-398. 